\title{
Fatty acids, epigenetic mechanisms and chronic diseases: a systematic review
}

\author{
K. González-Becerra', O. Ramos-Lopez ${ }^{2,3}$, E. Barrón-Cabrera' ', J. I. Riezu-Boj ${ }^{2,4}$, F. I. Milagro ${ }^{2,4,5}$, \\ E. Martínez-López ${ }^{1,6^{*}}$ and J. A. Martínez ${ }^{2,4,5,7}$
}

\begin{abstract}
Background: Chronic illnesses like obesity, type 2 diabetes (T2D) and cardiovascular diseases, are worldwide major causes of morbidity and mortality. These pathological conditions involve interactions between environmental, genetic, and epigenetic factors. Recent advances in nutriepigenomics are contributing to clarify the role of some nutritional factors, including dietary fatty acids in gene expression regulation. This systematic review assesses currently available information concerning the role of the different fatty acids on epigenetic mechanisms that affect the development of chronic diseases or induce protective effects on metabolic alterations.
\end{abstract}

Methods: A targeted search was conducted in the PubMed/Medline databases using the keywords "fatty acids and epigenetic". The data were analyzed according to the PRISMA-P guidelines.

Results: Consumption fatty acids like n-3 PUFA: EPA and DHA, and MUFA: oleic and palmitoleic acid was associated with an improvement of metabolic alterations. On the other hand, fatty acids that have been associated with the presence or development of obesity, T2D, pro-inflammatory profile, atherosclerosis and IR were n-6 PUFA, saturated fatty acids (stearic and palmitic), and trans fatty acids (elaidic), have been also linked with epigenetic changes.

Conclusions: Fatty acids can regulate gene expression by modifying epigenetic mechanisms and consequently result in positive or negative impacts on metabolic outcomes.

Keywords: DNA methylation, Obesity, Epigenetic, N-3 fatty acids, Butyrate, Insulin resistance, Metabolic alterations

\section{Introduction}

Nutriepigenomics is an emerging scientific area that studies the relationships between nutrition and the epigenetic. In recent years, several studies have focused on the description of different dietary components that can contribute to modify epigenetic processes and consequently, modulate gene expression and metabolic responses. These epigenetic modifications may be associated with the susceptibility to develop non-communicable chronic diseases (NCCD), such as obesity, lipid disorders, insulin resistance (IR), cardiovascular diseases (CVD), type 2 diabetes (T2D), and some types of cancer [1].

\footnotetext{
* Correspondence: erikamtz27@yahoo.com.mx

${ }^{1}$ Institute of Traslational Nutrigenetics and Nutrigenomics, Health Sciences University Center, University of Guadalajara, Guadalajara, Jalisco, Mexico

${ }^{6}$ Department of Molecular Biology in Medicine, Health Sciences University Center, University of Guadalajara, Sierra Mojada 950, 44340 Guadalajara, Jalisco, Mexico

Full list of author information is available at the end of the article
}

Epigenetics is defined as the study of heritable changes in DNA and histones without concomitant alterations in the nucleotide sequence $[2,3]$. These modifications can affect gene expression and the phenotype in response to environmental stimuli $[2,4]$. The main epigenetic mechanisms include DNA methylation, histone modifications, and non-coding RNAs such as microRNAs (miRNAs), among others [5].

Epigenetic changes are plastic genomic processes that are influenced by endogenous and exogenous factors, and these modifications could be potentially propagated from one generation to the next [6]. Thus, it might be possible to reprogram epigenetic modifications that are associated with an increased disease risk through nutritional or lifestyle changes. In this context, a number of nutritional factors involved in epigenetic modifications have been reported, including methyl donors, amino acids, vitamins and minerals, polyphenols, and other phytochemicals, and fatty acids (FA) [7]. 
Regarding FA, some studies have demonstrated the effects of n-3 and n- 6 polyunsaturated acids (PUFA) on DNA methylation, including specific responses of eicosapentaenoic acid (EPA), docosahexaenoic acid, (DHA), [8] and arachidonic acid (AA) [9]. However, the mechanisms underlying the effects of different types of FA on epigenetic landmarks, are still not completely known. The most extensively studied FA is butyric acid, a shortchain fatty acid produced in the anaerobic colonic fermentation that can act as an inhibitor of histone deacetylases (HDAC) and has been associated with histone deacetylation [10].

In the last years, the profile of FA intake has dramatically changed from diets with high monounsaturated (MUFA) and polyunsaturated fatty acid (PUFA) content, to a Westernized dietary pattern characterized by a high content in saturated fatty acids (SFA) and trans fatty acids (TFA) and poor in n-3 PUFA [11]. This nutritional transition is associated with the rising prevalence of NCCD, which have been recently associated with aberrant epigenetic changes and are now major cause of death worldwide [12].

It is well known that obesity, CVD, IR, T2D, cancer and other NCCD involving multifactorial and genetic interactions [13]. In this context, the study of pathophysiological, genetic and epigenetic processes could help to design new integral strategies for the prevention and treatment of these conditions [14]. Therefore, the objective of the present review is to describe the role of dietary FA in the modulation of epigenetic landmarks in relation to the development of NCCD, and their ability to reverse the epigenetic landscape.

\section{Methods}

This systematic review has been developed according to the Preferred Reporting Items for Systematic Reviews and Meta-Analyses Protocol (PRISMA-P) guidelines [15]. Literature search was performed using PubMed/ Medline databases and just English papers were considered. According to PRISMA-P procedures, the key words "FA and epigenetics" (including SFA, MUFA and PUFA) and the period of publication "2010-2017" were used as filters. At this stage, a total of 620 articles were identified. A flow diagram showing the selection process is depicted (Fig. 1).

\section{Eligibility criteria}

First inclusion criteria were articles analyzing the effects of FA on epigenetics mechanisms. In this section, 438 articles were removed because do not include interactions between epigenetics and FA. In a second step, articles not focused on the effect of metabolic alterations through epigenetic mechanisms in response to FA intake or supplementation were also excluded $(n=63)$.
Subsequently, articles showing inconsistent results, did not fulfill quality criteria or using valproic acid (considered a drug), were eliminated $(n=71)$. Lastly, articles that did not specify the type of FA intervention were also excluded $(n=17)$. The final analysis included 31 articles; however, seven additional articles obtained from reference lists were also incorporated in this review (Fig. $1)$.

\section{Data extraction, data elements}

Relevant information from all 38 papers was analyzed using a standardized data extraction template where two co-authors were specifically involved. Data about the type of FA used for treatment, the study model, the underlying epigenetic mechanism as well as the main results related to metabolic outcomes, were reported, more details are shown in Additional file 1.

\section{Quality assessment}

Study quality was evaluated according to Jadad scale for clinical trials and it was considering randomization, blinding and withdrawals and dropouts. The selection criteria of the articles had to meet at least 3 criteria to be included. In this review, two authors evaluated the quality of papers and to resolve some disagreements all the author make a consensus procedure to define if the article full fill the criteria for be included in the systematic review.

\section{Data analysis}

The acquired information was organized based on the type of FA and experimental model analyzed. The data were sorted according to fatty acids subtypes; firstly, unsaturated fatty acids were described (PUFA: $n-3, n-6$ and MUFA: oleic) (Table 1). Then, saturated and trans fatty acids were sorted in a second category (Table 2). Butyrate was independently analyzed from other FA because it is a product of anaerobic colon fermentation (Table 3). Finally, articles including more than one type of FA were grouped together (Table 4).

\section{Results \\ Unsaturated fatty acids Human studies}

N-3 PUFA In the last years, many investigations have focused on the effects of n-3 PUFA in the prevention and treatment of different metabolic alterations. Thus, Tremblay and collaborators investigated the effect of $n-3$ PUFA supplementation in overweight and obese subjects on epigenetic modifications [16]. They found that after a 6-month supplementation 308 CpG sites (231 genes) had different methylation pattern, of which $286 \mathrm{CpG}$ sites were hypermethylated representing $93 \%$ of the 


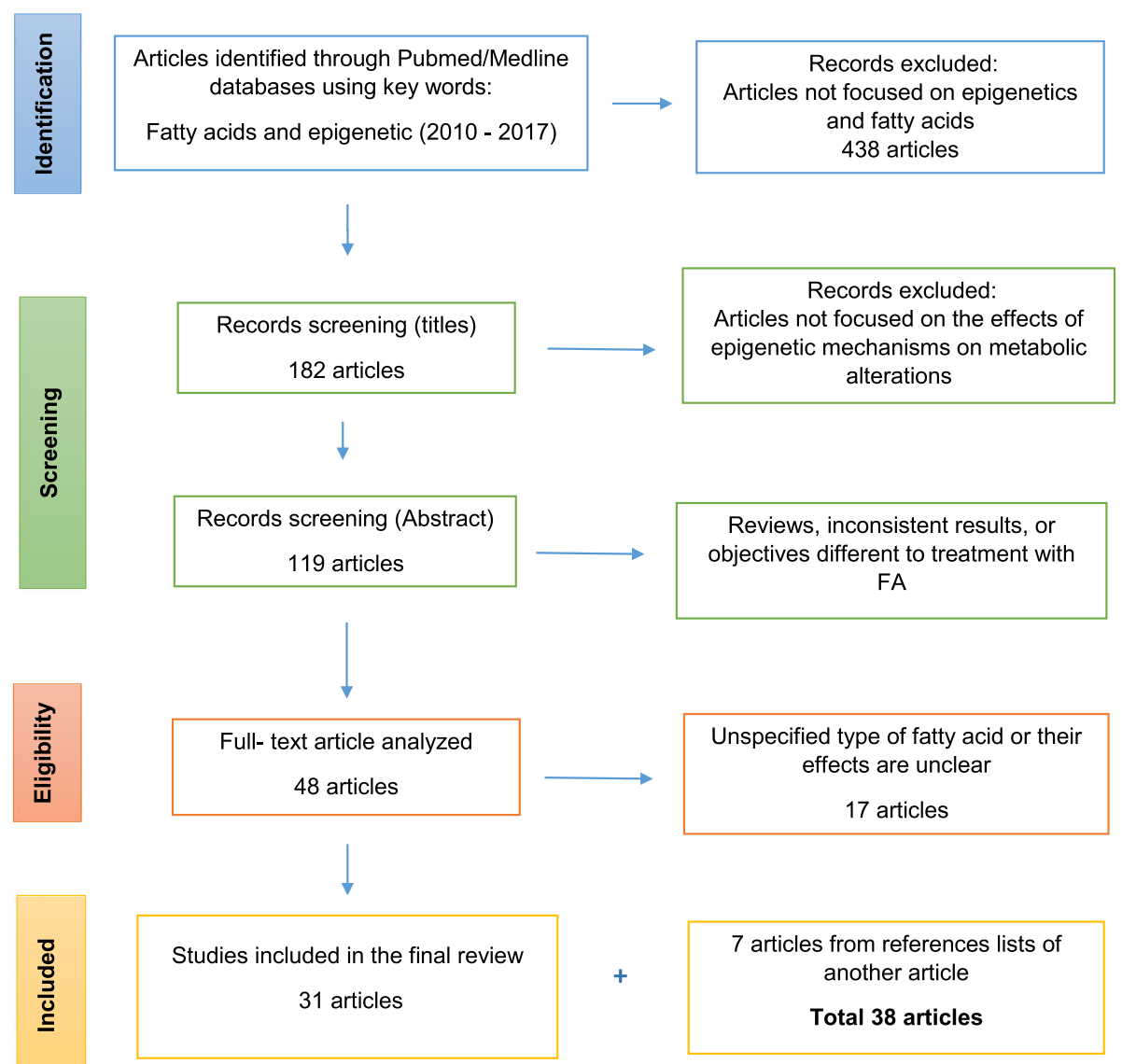

Fig. 1 PRISMA flow diagram. Summarizing the selection of papers included in this review (using the term "FA and epigenetics"). Human studies, animal models, and in vitro experiments, were included. FA: Fatty acids

changes after the supplementation and 22 were hypomethylated (just 7\%), using ingenuity pathway analysis system it was reported these epigenetic changes were related to pathways associated with inflammatory and immune responses, lipid metabolism, T2D, and cardiovascular signaling [16].

Another study in obese subjects under an energyrestricted diet supplemented with n-3 PUFA-rich fish oil conducted by do Amaral and collaborators found that the methylation levels of PDK4 (Pyruvate Dehydrogenase Kinase 4) CpG sites -222 and -50 and FADS1 CpG $25-22-20$ were increased in the group supplemented with fish oil. Furthermore, n-3 PUFA supplementation was accompanied by improved weight loss, which was associated with changes in the methylation pattern of one specific CpG site in CD36, a gene that encodes a membrane glycoprotein that plays a relevant role in lipid metabolism and may be implicated in obesity-related complications like glucose intolerance and T2D [19].

On the other hand, Aslibekyan et al. investigated the effect of n-3 PUFA intake in a population of Yupik natives, considering that this population had a higher intake of fish-derived n-3 PUFA [17]. For this study, the population was categorized in higher and lower deciles of a nitrogen stable isotope ratio $(\delta 15 \mathrm{~N})$, which is a biomarker of n-3 PUFA intake and thus, n-3 PUFA plasma content. The authors found 27 differentially methylated CpG sites at biologically relevant regions that reached epigenome-wide significance and highlighted that DNA methylation may reduce FAS (apoptosis antigen 1) expression and, consequently, regulate lipid metabolism through the apoptotic pathway. Also, the methylation pattern of AHRR (Aryl-Hydrocarbon Receptor Repressor), a gene that is involved in oxidative stress, was affected by the n-3 PUFA intake, which was accompanied by a positive impact on glucose tolerance and insulin sensitivity [17].

In addition, Arpón et al. studied the effect of Mediterranean Diet (MedDiet) complemented with extra virgin olive oil (EVOO) or nuts on DNA methylation within PREDIMED (PREvención con DIeta MEDiterránea) study. They compared the two diets MedDiet + EVOO and MedDiet + nuts with a low-fat control group during five-year follow-up and found that MedDiet + nuts 


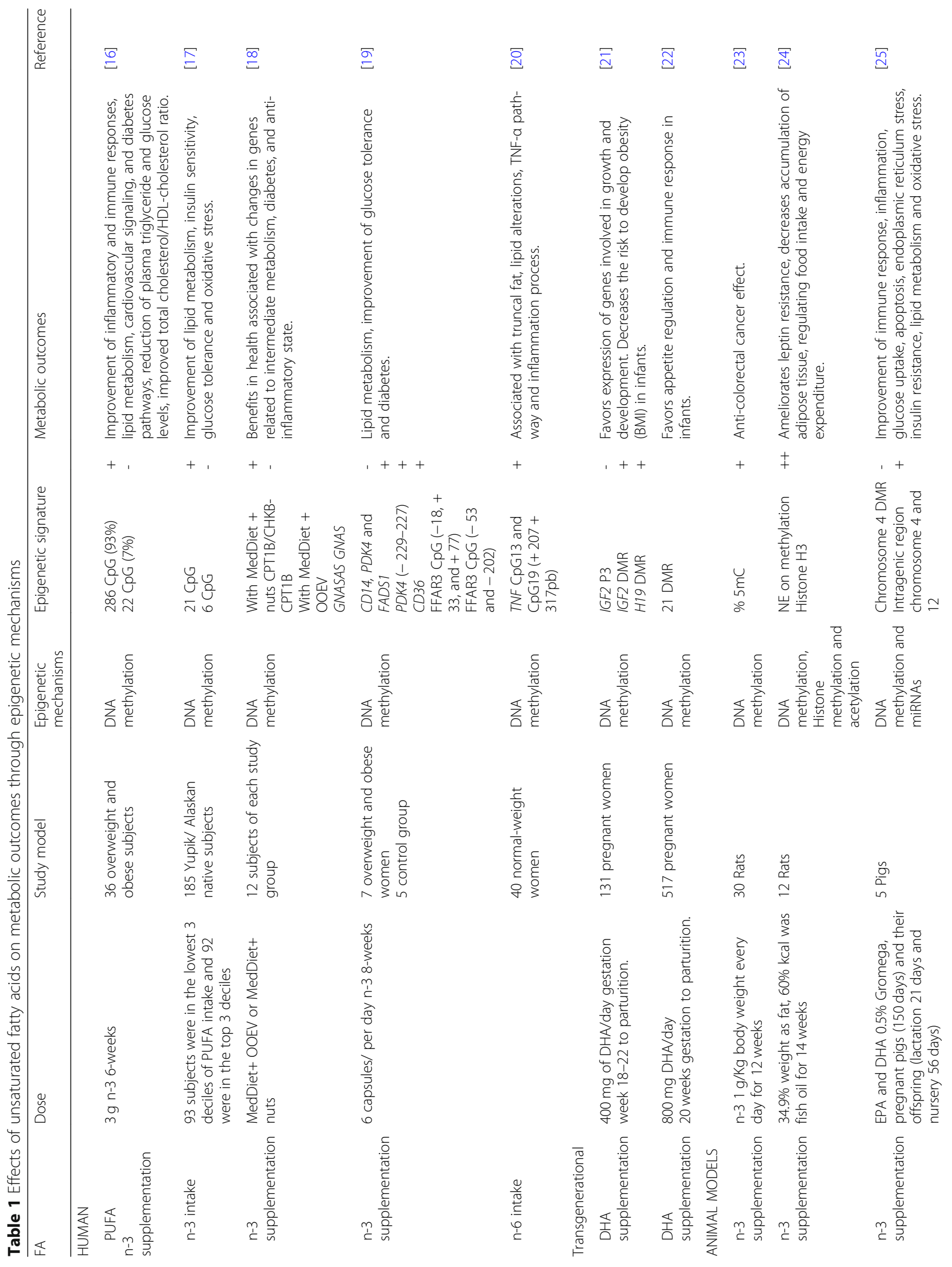




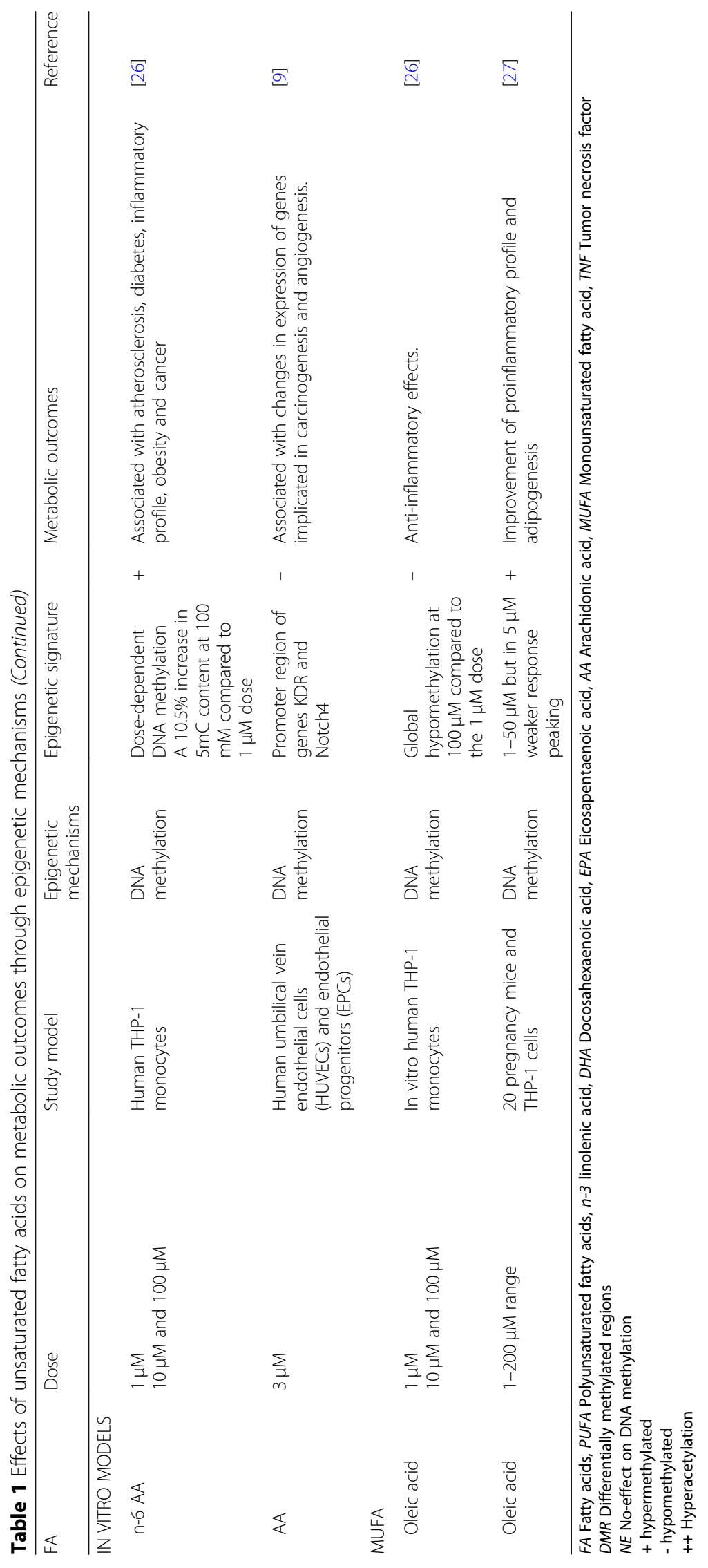




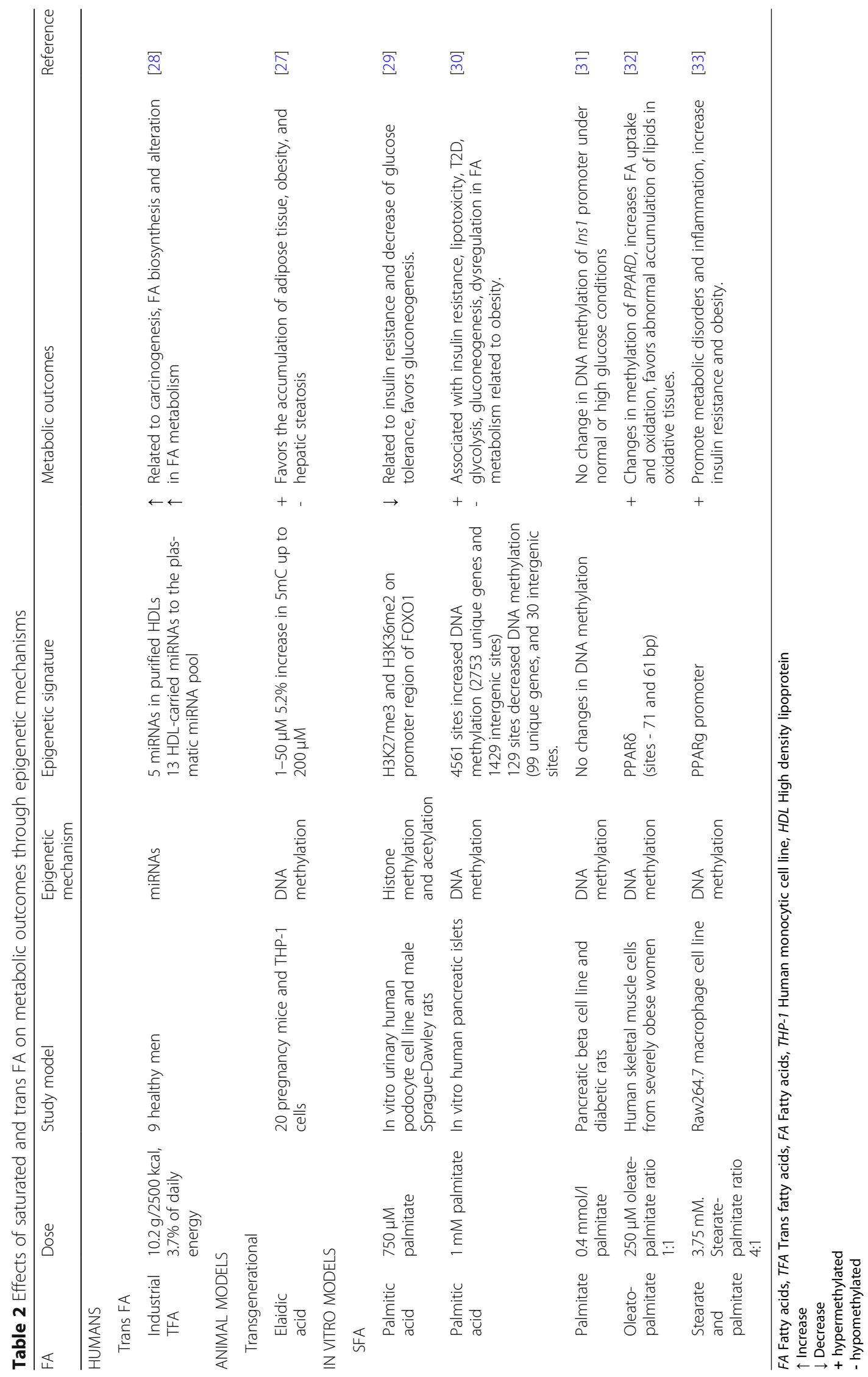




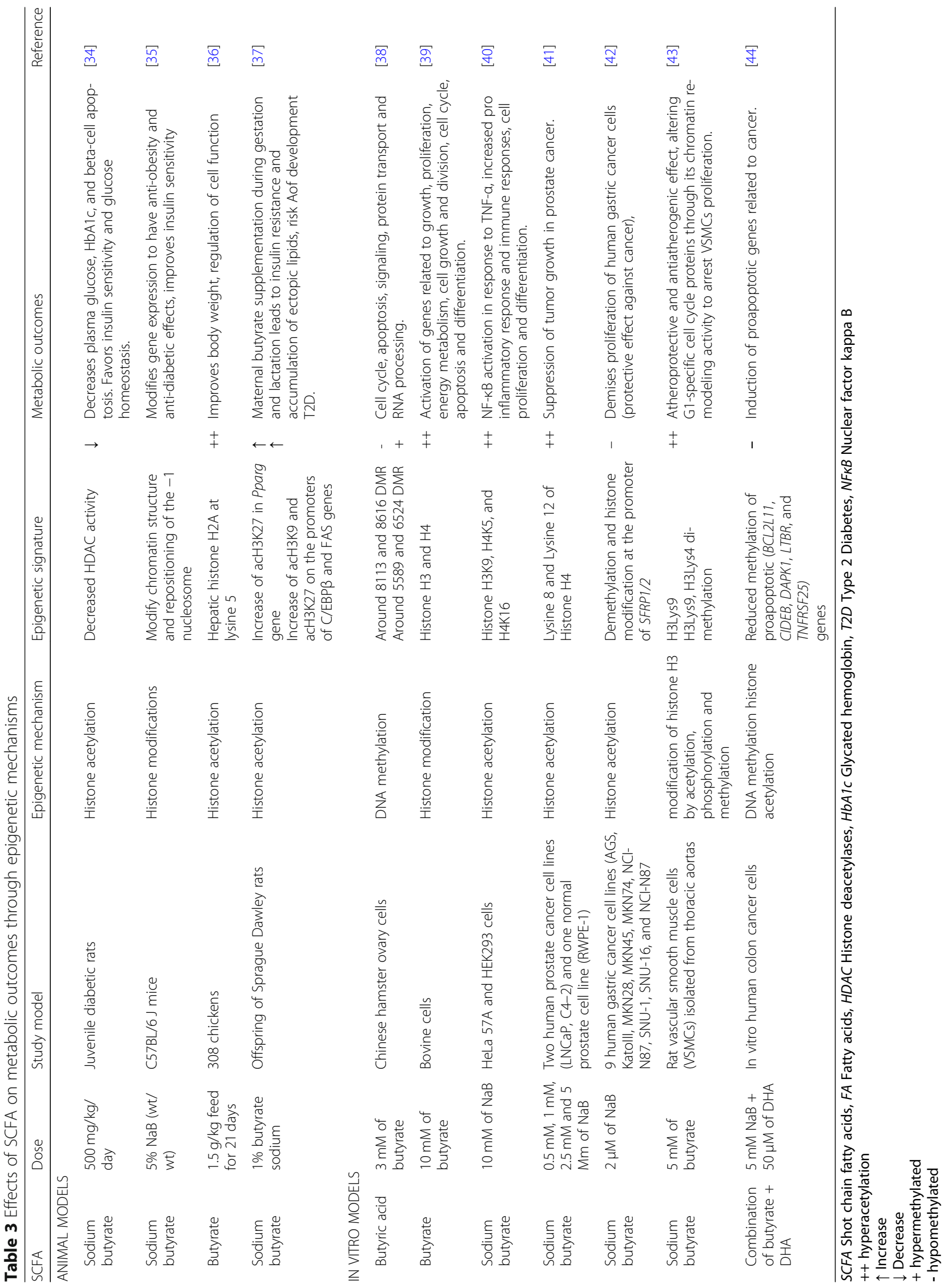




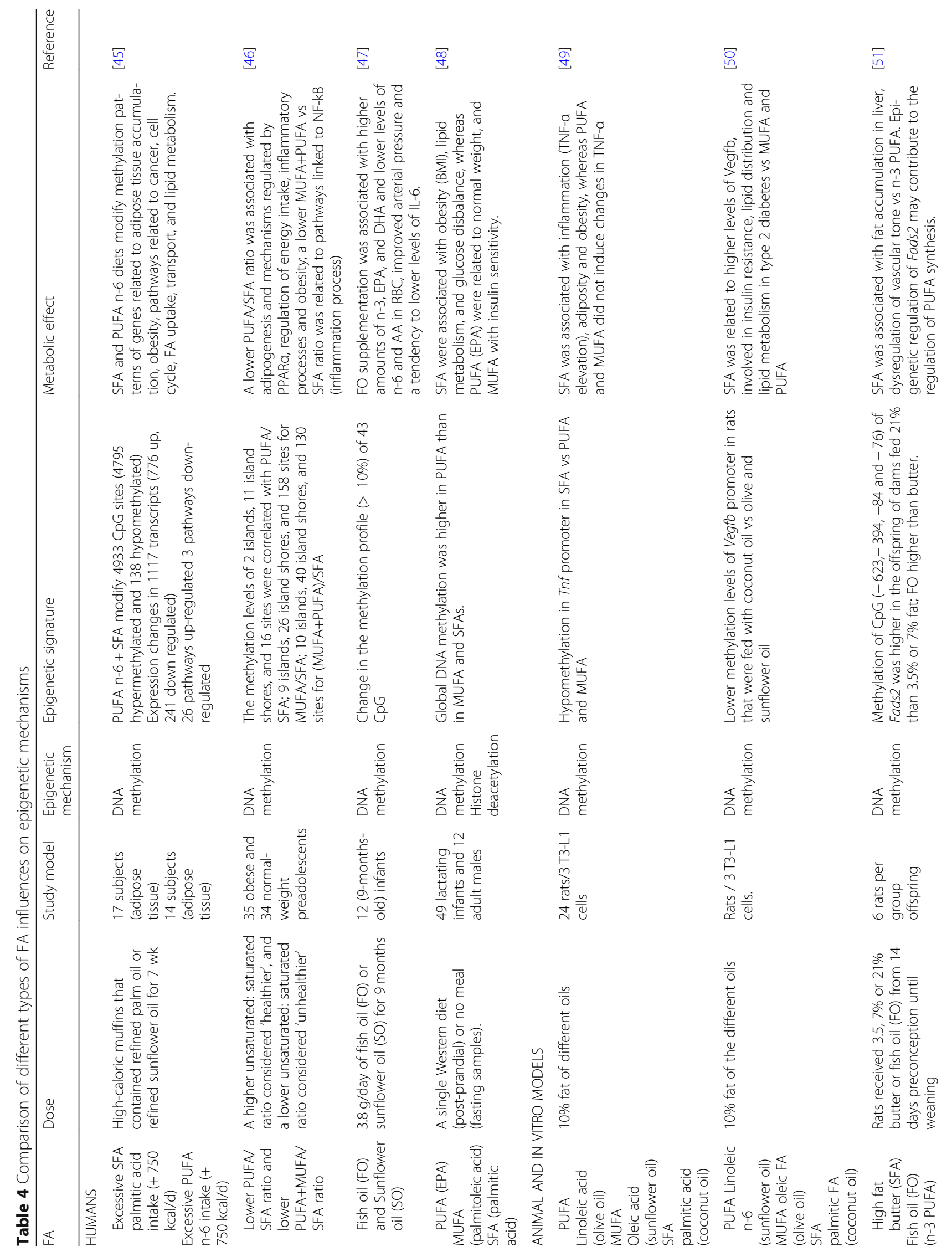




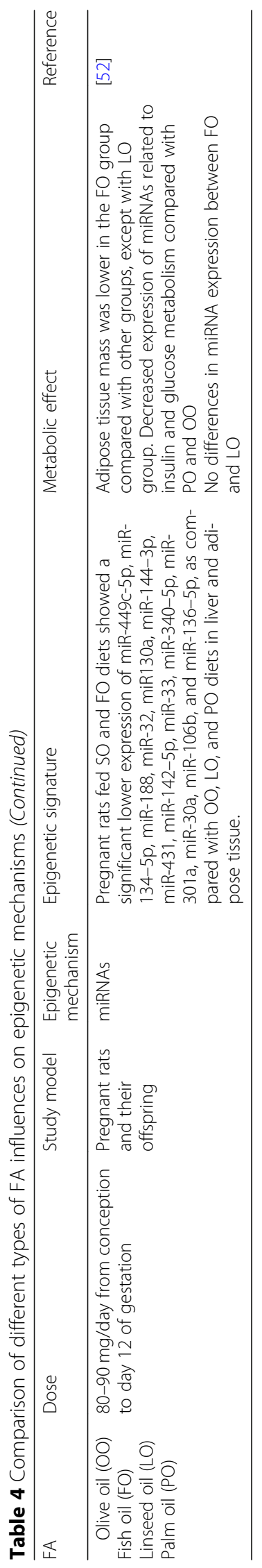


favors a hypermethylation of cg01081346 in CPT1B/ CHKB-CPT1B genes (Carnitine palmitoyltransferase 1B/ Choline kinase-like, Carnitine palmitoyltransferase 1B) and MedDiet + EVOO induce hypomethylation in cg17071192 in GNAS/GNASAS genes GNAS/GNASAS (Guanine Nucleotide Binding Protein, G Protein), however both diets were associated with intermediate metabolism as well as improve genes involved in diabetes and inflammation pathways [18].

Transgenerational studies Several investigations have reported the effects of $n-3$ PUFA supplementation (DHA) in the maternal diet on epigenetic changes in the offspring [21, 22]. Thus, Lee and collaborators demonstrated that DHA supplementation in pregnant women demonstrated higher methylation levels of IGF2/H19 in their offspring versus control group, a gene that is crucial for the correct fetal growth, development, and metabolism of the infants and this effect was dependent on the maternal BMI before pregnancy. Furthermore, IGF2/ H19 DMR methylation changes have also been associated with paternal obesity or the risk of overweight, diabetes or some types of cancer in early life [21].

On the other hand, Van Dijk et al. found in a large randomized controlled trial that DHA supplementation during pregnancy did not significantly affect the global methylation pattern, although they identified 21 differentially methylated regions (DMRs) at birth (this difference was sex-dependent) in genes implicated in diverse functions including lipid exchange between membranes (ESYT3), appetite regulation $(C C K)$, and immune function (RAET1L and LTB) among others [22].

N-6 PUFA A trial by Hermsdorff et al. showed that AA intake (an n-6 PUFA) was related with higher values of truncal fat, BMI, and waist circumference in women [20]. Moreover, they found a negative correlation between the methylation of $T N F$ and the levels of this proinflammatory cytokine. In particular, the hypermethylation of two CpGs of this gene $(+207$ and $+317 \mathrm{pb})$ was associated with the under expression of the gene, and the result of a linear regression model suggest this methylation levels of TNF $\alpha$ promoter were associated with n-6 PUFA intake, suggesting a complex nutriepigenomic interaction that could exacerbate the proinflammatory state [20].

\section{Animal models}

N-3 PUFA In a study to explore whether n-3 PUFA affects DNA methylation levels in colorectal cancer, rats were fed with n-3 PUFA during tumor induction [23]. The main results showed that the tumor incidence in rats fed the n-3 PUFA-enriched diet was lower than in the non-treated group, demonstrating that the anti- tumorigenic effect of n-3 PUFA was mediated by an increase of DNA methylation [23]. On the other hand, Shen et al. observed that n-3 PUFA could modulate histone modifications by inhibiting enzymes that catalyze or alter the availability of substrates that are required for enzymatic reactions. A significantly lower activity of DNMT1 (DNA methyltransferase 1) and MBD2 (Methyl-CpG-binding domain protein 2) enzymes was observed in mice fed the n-3 PUFA-enriched diet. This outcome was accompanied by an increase in $\mathrm{H} 3$ acetylation, lower binding levels of HDAC1, HDAC2, HDAC6 and higher levels of methyl-H3K4 and -H3K9. Hence, the authors concluded that the regulation of leptin expression by $n-3$ PUFAs is mediated by epigenetic factors, such as MBD2 and histone modifications. Furthermore, n-3 PUFA supplementation in high fat-fed rodents decrease leptin mRNA expression, ameliorate leptin resistance, and decreased the differentiation and proliferation of adipocytes and their storage capacity [24].

Transgenerational studies A genome-wide methylation study was conducted in pigs to determine the effect of prenatal and postnatal n-3 PUFA supplementation (throughout gestation, lactation, and post-weaning periods) on the methylation pattern of the offspring [20]. Different methylation patterns were observed when comparing the supplemented and non-supplemented groups in chromosome 4, finding a hypomethylated DMR in supplemented groups; conversely, hypermethylation was detected in two intergenic regions of chromosomes 4 and 12. The authors concluded that the genes differentially methylated in the offspring were mainly involved in pathways that were improved by the n-3 PUFA supplementation, such as apoptosis, endoplasmic reticulum stress, glucose and insulin homeostasis, immune function, inflammatory profile, glucose uptake, lipid metabolism, and oxidative stress [25]. On the other hand, another study reported that EPA was able to inhibit the expression of lipogenic genes while upregulating genes involved in fatty acid oxidation [53].

In conclusion, the effects of PUFA depend upon the subtype of FA, (n-6 or n-3; AA and EPA-DHA, respectively), the doses, the sources, and the way of administration (in foods or as nutraceutical). In this sense, more studies are needed in humans and animal models, to uncover the epigenetic effects of PUFA in relation to their beneficial role in NCCD.

\section{In vitro models}

N-6 PUFA Silva-Martínez et al. studied the effect of AA on global DNA methylation and gene expression in cultured human THP-1 monocytes. The cell stimulation was for $24 \mathrm{~h}$ using different concentrations of AA $(1,10$, 
or $100 \mu \mathrm{M})$. The results showed that AA induced a dose-dependent DNA hypermethylation peak at the 100 $\mathrm{mM}$ dose and the AA stimulation could alter the methylation profile in a similar way that was reported with palmitic acid (saturated acid that was related with aberrant epigenetic changes). This methylation profile was associated with the alteration of pathways involved in metabolic diseases like atherosclerosis, T2D, obesity, the proinflammatory profiles, and some types of cancer [26].

Another research group employed human umbilical vein endothelial cells (HUVECs) and endothelial progenitors (EPCs) to study the effect of AA on DNA methylation and the expression of genes related to angiogenesis as a mechanism involved in the carcinogenesis process [9]. After the stimulation with AA $(3 \mu \mathrm{M})$ for $24 \mathrm{~h}$, the expression of 18 proangiogenic genes was affected. The authors concluded that the beneficial effect of AA on carcinogenesis may be due, at least in part, to changes in the expression of angiogenic genes, which may be mediated by changes in DNA methylation [9].

MUFA In addition to AA, Silva-Martínez et al. also evaluated the impact of oleic acid (OA) on cultured human THP-1 monocytes [26]. This study demonstrated that OA had an opposite effect than AA, inducing a global hypomethylation and consequently an expression pattern that were related with an improvement of the inflammation profile [26].

As previously described for PUFA, the epigenetic effects of MUFA depended on the subtype of FA and the doses. For example, OA, whose principal sources are vegetable, oils like olive oil, can ameliorate processes related to atherosclerosis, inflammation, T2D and obesity through epigenetic modifications [26].

By other hand, palmitoleic acid is an n-7 MUFA that is biosynthesized from palmitic acid (SFA) whose principal sources are of animal origin and dairy products [54]. Thus, FA can also alter the epigenome, affecting genes associated with prevention of insulin resistance and diabetes and improved lipid and glucose metabolism [55].

\section{Saturated and trans fatty acids Human studies}

Trans FA Dietary trans-fatty acids (TFA) are associated with an increased risk of metabolic diseases. Some of these effects can be mediated by epigenetic mechanisms. For example, a study in humans associated industrial TFA consumption with HDL-carried miRNA concentrations and plasmatic HDL-c levels [28]. The diet rich in industrial TFA altered the concentrations of 5 miRNA in purified HDL and also contributed to $13 \mathrm{HDL}$-carried miRNA to the plasmatic miRNA pool. These miRNAs modified through the TFA- enriched diet were associated with lipid metabolism and extracellular matrix receptor interaction, suggesting an important role of miRNAs in plasma lipid metabolism regulation [28].

\section{Animal models \\ Trans FA}

Transgenerational Flores-Sierra et al. studied the effects of elaidic acid (EA) supplementation during either pregnancy or lactation in C57BL/6 mice. In both cases, EA supplementation was observed to induce global DNA methylation in the adipose tissue of the offspring 3 months after birth, and it was associated with weight gain and adipose tissue accumulation [27].

\section{In vitro models}

Trans FA The study by Flores-Sierra et al. evaluated the effect of TFA elaidic acid (EA; tC18:1) on global DNA methylation and gene transcription in cultured human THP-1 monocytes. They found a biphasic dosedependent response and global hypermethylation was described in the $1-50 \mu \mathrm{M}$ concentration range, whereas global hypomethylation was observed in concentrations up to $200 \mu \mathrm{M}$. The main results showed that EA affected the expression of genes related to pro-inflammatory and adipogenic profiles, but it also affected DNA methylation, suggesting that EA can target gene-body or intergenic regulatory elements [27].

Saturated FA Investigations carried out by Kumar and et al. studied models of IR in human-urine derived podocyte-like epithelial cells (HUPECs) and in male Sprague-Dawley rats, which were fed a high-fat diet. HUPECs were stimulated with $750 \mu \mathrm{M}$ palmitate, a concentration that is two to three times higher than the palmitate level in normal non-esterified fatty acids (NEFA) [29]. The results showed that an excess of circulating palmitate generated a FA-induced metabolic memory possibly by altering the levels of H3K36me2 and $\mathrm{H} 3 \mathrm{~K} 27 \mathrm{me} 3$ on the FOXO1 promoter region, increasing its activity. In conclusion, palmitate favored IRinduced gluconeogenesis and hyperglycemia, and this effect persisted even after normalization of lipid levels both in vitro and in vivo, representing cellular metabolic memory [29].

In this context, other researchers have analyzed the effect of palmitate on genome-wide mRNA expression and DNA methylation, in human pancreatic islets in vitro [30]. They reported an increase in the average global DNA methylation in different gene regions including TSS1500, 5'UTR, gene body, 3'UTR and intergenic regions, and a small decrease in global methylation in TSS200 and the 1st exon. Palmitate altered DNA 
methylation levels in 290 genes, 73 of which were related to BMI. The expression of 1860 genes were also affected by palmitate, including genes involved in T2D (TCF7L2, GLIS3, HNF1B, and SLC3OA8), and genes associated with glycolysis and gluconeogenesis, FA metabolism dysregulation, and one carbon pool by folate [30].

On the other hand, Ishikawa et al. differed from the other reports, finding that palmitate did not affect DNA methylation levels of the Ins1 gene promoter in normal or high glucose conditions, which could be due to differences in the doses and genes considered in both studies [31].

Furthermore, Maples et al. found that oleate-palmitate (250 $\mu \mathrm{M}$ oleate-palmitate 1:1 ratio) favored DNA methylation in relation to PPAR $\delta$ expression in human skeletal muscle cells (HSkMC) from lean and severely obese women. However, this increase in DNA methylation was lower in HSkMc from obese women, suggesting that obesity can activate transcriptional regulators of FA oxidation in response to FA exposure. In conclusion, the occurrence of different epigenetic alterations in HSkMC after lipid stimulation suggests that a specific epigenetic programming may occur in obese subjects as a response to their own environmental conditions [32].

The effects of stearate and palmitate on the methylation of Pparg promoter were investigated in Raw264.7 murine macrophages. The incubation with these SFA increased IL-4 levels and the methylation of Pparg, suggesting that Pparg hypermethylation could mediate the proinflammatory effects of these SFA and contribute to IR in obesity [33].

The harmful effects of some SFA are well known. For example, palmitic and stearic FA have been involved in pro-inflammatory and metabolic alterations. Different investigations have demonstrated their contribution to the modulation of DNA methylation and histone acetylation in relation to their effects on IR, obesity, hyperglycemia, T2D, lipotoxicity, dysregulation of lipid metabolism, and abnormal lipid accumulation [29-33]. In the last years, the increased consumption of processed and industrialized food, with higher amounts of SFA and TFA, has been associated with inflammation, adipogenesis, abnormal accumulation of adipose tissue, alterations in lipid metabolism, and carcinogenesis processes, which could be mediated by changes in DNA methylation, covalent histone modifications, and some miRNAs.

Short-chain fatty acids Short-chain fatty acids (SCFA) are products of microbial fermentation that can be absorbed in the large intestine [56]. These SCFA can modify epigenetic landmarks (i.e., histone acetylation) and modulate the expression of genes related to pathways associated with cancer, lipid metabolism, glucose homeostasis, and insulin sensitivity, among others. For example, sodium butyrate $(\mathrm{NaB})$ has been demonstrated to inhibit HDAC activity [57-59].

\section{Animal models}

Sodium butyrate (NaB) Research by Khan et al. studied the effect of $\mathrm{NaB}$ supplementation in juvenile diabetic rats, demonstrating a role for $\mathrm{NaB}$ as an HDAC inhibitor associated with a decrease in glucose and Hbalc, favoring insulin sensitivity and reducing the risk of developing diabetes [34].

Protective anti-obesity and anti-diabetic effects of $\mathrm{NaB}$ have been also reported in a model of $\mathrm{C} 57 \mathrm{BL} / 6 \mathrm{~J}$ mice exposed to a high-fat diet [35]. $\mathrm{NaB}$ prevented the increase of body weight and adiposity and improved insulin sensitivity, increasing the percentage of type-1 fibers and improving acylcarnitine profiles in muscle [35]. In this context, Mátis et al. also found in chickens that $\mathrm{NaB}$ improved body weight and favored cell function regulation, which was mediated by epigenetic changes, such as histone hyperacetylation [36].

Transgenerational In a transgenerational study, Huang et al. demonstrated that an unbalanced maternal diet was determinant in the development of IR and obesity in the offspring. Moreover, they analyzed the effect of maternal butyrate supplementation on insulin sensitivity and lipid metabolism in the skeletal muscle of the offspring. The rats received butyrate diet $(1 \% \mathrm{NaB})$ during gestation and lactation for 60 days. The offspring of dams that were supplemented with $\mathrm{NaB}$ had impaired glucose tolerance and a higher HOMA index (insulin resistance), which was associated with an overexpression of lipogenic genes. This was accompanied by an increase in histone H3 (Lys9) and H3 (Lys27) acetylation in relation to lipogenic genes in the skeletal muscle of the adult offspring. The authors concluded that, in this model, butyrate impaired lipid metabolism and insulin sensitivity in the offspring [37]. This negative effect of butyrate was inconsistent with other investigators, suggesting that dose and duration might be important, and indicating that more studies are necessary to elucidate the role of $\mathrm{NaB}$ and other SCFA in the prevention or treatment of chronic diseases.

\section{In vitro models}

Chinese hamster ovary $(\mathrm{CHO})$ cells were used to analyze the effect of $\mathrm{NaB}$ on the transcriptome and epigenome. In this study, $\mathrm{NaB}$ induced hypomethylation in genes belonging to pathways associated with the cell cycle, signaling and apoptosis, whereas hypermethylation was observed in genes implicated in protein transport and RNA processing. On the other hand, genes related to protein biosynthesis, the differentiation process and 
RNA metabolism, were both hyper and hypomethylated. Besides, authors hypothesized that the affected gene regions presented regulatory regions closely linked with the cellular response to butyrate stimulation [38].

Another study performed in bovine cells analyzed the effect of $\mathrm{NaB}$ supplementation on histone modifications. The main findings of the investigation were that the inhibition of HDAC caused by $\mathrm{NaB}$ promoted hyperacetylation of histones and modified the expression of genes associated with cell growth, proliferation, energy metabolism, cell cycle, apoptosis, and differentiation [39].

Likewise, another study found that both, butyrate and propionate were able to increase histone acetylation in HELA and HEK293 epithelial cells, and enhance NF-kB activation (in response to TNF- $\alpha$ ) by means of the induction of toll-like receptors (TLRs) These SCFA had an effect on the proinflammatory response, cell proliferation and differentiation, redirection of innate immune response, and cytokine/chemokine expression [40].

Paskova et al. demonstrated that $\mathrm{NaB}$ was able to modify the expression of androgen receptors in prostate cancer cells through an increase of H4 (Lys8) and H4 (Lys12) acetylation, favoring the suppression of tumor growth. However, this effect was minimal in normal cells, suggesting a protective role of $\mathrm{NaB}$ in the development of prostate cancer mediated by epigenetic modifications [41].

Consistent with this finding, other authors have reported protective effects of $\mathrm{NaB}$ in human gastric cancer cells, inducing demethylation and histone modifications at the promoter region of SFRP1/2, and restoring SFRP (Secreted Frizzled-Related Protein) expression in human gastric cancer cells. The authors proposed that $\mathrm{NaB}$ induced apoptosis, favored complex formation, promoted caspase activation, and blocked the potential of cancer cells [42].

Finally, an in vitro study combining $5 \mathrm{mM} \mathrm{NaB}$ plus $50 \mu \mathrm{M}$ DHA, evaluated histone modification and DNA methylation in genes involved in apoptosis. It was demonstrated that this combination had a hypomethylation effect on proapoptotic genes (Bcl2l11, Cideb, Dapk1, $L t b r$, and Tnfrsf25) and an increase in global $\mathrm{H} 4$ histone acetylation in cells treated with $\mathrm{NaB}$ combined with DHA; this induction of apoptosis had an anticancer effect [44].

Other authors studied the effects of $\mathrm{NaB}$ on histone modifications and its consequence on G1-specific cell cycle regulators in vascular smooth muscle cells (VSMC), trying to explain the interaction between chromatin remodeling and the antiproliferative action of butyrate. In this model, $\mathrm{NaB}$ acted as an HDAC inhibitor and caused a reorganization of chromatin, affecting the expression of negative and positive cell cycle regulators and arresting VSMC proliferation. Hence, $\mathrm{NaB}$ was considered a possible therapeutic agent against atherosclerosis [43].

The metabolic effects of butyrate are controversial because some studies have reported positive outcomes, such as a reduction in plasma glucose levels and HBA1c, and an improvement in insulin sensitivity and glucose homeostasis, preventing the increase of body weight and adiposity and inducing proapoptotic genes related to cancer. On the other hand, other studies have described negative effects of butyric acid, including IR, increased risk of T2D, lipid accumulation and a pro-inflammatory profile. Hence, more studies are needed to elucidate the metabolic effects of SCFA and the underlying epigenetic mechanisms, such as HDAC inhibition, in order to clarify their role as therapeutic tools against metabolic alterations and chronic diseases.

\section{Comparison of different types of fatty acids Human studies}

In order to analyze the effects of excessive palmitic acid and n-6 PUFA intake, subjects were instructed to continue with their habitual diet just with the addition of an extra high calorie (750-kcal) muffin rich in either palmitic acid $(n=17)$ or n-6 PUFA-rich sunflower oil $(n=14)$. An adipose tissue biopsy was obtained before and after the intervention period (7 weeks). In particular, SFA overfeeding increased the mean methylation of 125 genes and PUFA overfeeding changed the mean methylation of 1797 genes, only 47 genes overlapped between the two diets, which ones were related to adipose tissue accumulation, obesity, FA uptake, transport, and lipid metabolism insulin resistance and inflammation pathways. These results suggest that DNA methylation may be involved in the individual response to FA overfeeding [45].

Voisini et al. studied the impact of different ratios of PUFA, MUFA and SFA in 91 Greek preadolescents (< 10 years). They analyzed the effects of low PUFA:SFA ratio, low MUFA:SFA and low MUFA+PUFA:SFA ratios on genome-wide DNA methylation. The genes altered in the lower PUFA:SFA ratio were associated with adipogenesis, gene regulation by PPAR $\alpha$, regulation of energy intake, the inflammatory process and obesity. The low MUFA+PUFA:SFA ratio was related to pathways linked to NF-kB (inflammation process). These results suggest that different types of FA have different effects on the epigenome, leading to different physiological responses [46].

On the other hand, Lind et al. designed a study encompassing 133 (9 month-old infants) that were supplemented with a teaspoon of fish oil (1.5 g/day n-3, 400 mg DHA and $1100 \mathrm{mg}$ EPA) or sunflower oil ( $3.8 \mathrm{~g} /$ day) during a 9 month period. They analyzed global DNA methylation and did not find statistical differences between groups; however, they reported that $43 \mathrm{CpG}$ had a $10 \%$ difference or more in the absolute methylation level 
between groups, demonstrating differential effects of both FA. In the PUFA group, they found a higher amount of n-3, EPA and DHA, but lower levels of $n-6$ and AA in red blood cells (RBC), which was associated with an improvement of arterial pressure and a tendency of lower IL-6 levels [47].

Another study including two different human cohorts, lactating infants, and adult men, attempted to assess if there was an association between DNA methylation and different types of FA, in both fasting and the postprandial state. In the postprandial state, the participants received a representative meal of the western diet (hamburger, fries and coke) and blood was taken after the meal consumption and every $2 \mathrm{~h}$ until $6 \mathrm{pm}$. In the fasting day, volunteers were maintained in the fasted state from 10 am until $6 \mathrm{pm}$ and blood was taken every $2 \mathrm{~h}$. Furthermore, the subjects were separated according to BMI in normal-weight, overweight and obese. Results evidenced a different methylation pattern depending on the BMI and the fasting/postprandial state. The study found that DNA methylation and histone deacetylation mediated by PUFA were related to a cardioprotective and normal-weight status, in contrast to epigenetic landmarks modulated by MUFA (palmitoleic acid) and SFA (palmitic acid) that were associated with pathways implicated in obesity, dysregulation of lipid metabolism, and glucose misbalance [48].

\section{Animal and in vitro models}

A study in 34 rats and 3 T3-L1 cells compared the administration of different types of FA: sunflower oil rich in linoleic acid as PUFA, olive oil rich in oleic acid as MUFA, and coconut oil rich in palmitic acid as SFA. In rats, DNA methylation of the Tnf promoter was analyzed in the visceral adipose tissue. While both linoleic acid (PUFA) and oleic acid (MUFA) did not change Tnf methylation levels, palmitic acid increased $\operatorname{Tnf}$ methylation and was associated with inflammation, adiposity, and obesity. The study also concluded that FA may regulate adipocyte TNF- $\alpha$ levels through changes in the methylation levels of the Tnf promoter [49].

Moreover, Monastero et al. analyzed the dietary FAmediated epigenetic regulation induced by the Vascular Endothelial Growth Factor B (VEGF-B) in adipose tissue of rats and in 3 T3-L1 cell lines [50]. Rats fed with coconut oil presented higher levels of VEGF-B expression and levels of protein, which was associated with the methylation levels of the promoter. Rats fed sunflower oil showed the lowest levels of VEGF-B while higher VEGF-B levels were associated with IR and T2D, as well as an impaired lipid metabolism [50].

Transgenerational A trasgenerational trial was designed by Hoilea et al. to determine the effect of maternal FA consumption on the PUFA status and the epigenetic regulation of fatty acid desaturase 2 (Fads2) involved in PUFA synthesis. The dams received two different FArich foods, butter (rich in SFA) or fish oil (rich in n-3 PUFA) and afterwards, the offspring were evaluated. They found a negative correlation between Fads2 expression and the promoter methylation levels. The methylation level of Fads2 was higher in the fish-oil group that in the butter group, which was related to a higher accumulation of fat in the liver and a dysregulation of the vascular tone in the butter group. In conclusion, the type of FA affected the regulation of the PUFA synthesis through epigenetic mechanisms [51].

The type of FA can also affect other epigenetic mechanisms, such as the expression of miRNAs, which can modulate the expression of different genes [60]. A study in which pregnant rats were fed soybean oil, olive oil, fish oil, linseed oil, or palm oil diets from conception to day 12 of gestation, the aim was to analyze miRNA expression in adipose tissue and liver of dams and their offspring. The adipose tissue mass was lower in the fish oil and linseed oil groups compared with other groups. Some hepatic miRNAs, such as miR-192-5p, miR-10b5p, miR- 377-3p, miR-215, miR-21-5p and mir-26b- 5p, were downregulated by fish oil compared with olive oil and palm oil diets. These miRNAs are involved in insulin homeostasis and glucose metabolism. This study concluded that the maternal intake of diverse types of FA during pregnancy can modulate miRNA expression in both maternal and offspring tissues, relating to epigenetic mechanisms and phenotypic outcomes in the adult offspring [52]. Other studies found that a high-fat diet in pregnancy and lactation modulated hepatic miRNAs in the offspring [61, 62]. Hence, it is necessary to design more studies to clarify the role of FA in the modulation of miRNA expression and its association with metabolic alterations.

\section{Conclusions}

Over the last years, a growing number of investigations have been focused on the protective/beneficial effects of different FA, including n-3 PUFA and SCFA, in NCCD. The most consistent literature shows that some of these effects could be mediated by epigenetic mechanisms which play a role in the regulation of gene expression. In addition to n-3 PUFA and SCFA, other FA types, such as n-6 PUFA, MUFA, SFA, and TFA may also alter epigenetic mechanisms, and their effects are still under research. The results show that different types of FA have a different effect on the epigenome, mainly on DNA methylation; however, it is necessary to perform more studies focused on other epigenetic mechanisms, such as histone modifications and miRNAs and their subsequent effects on the regulation of gene expression. 
The existing results confirm that FA can influence DNA methylation (hyper or hypomethylation) as well as acetylation or deacetylation of histones, and miRNAs associated with the repression, or activation of genes. For example, n-3 PUFA (i.e., EPA-DHA), and MUFA (i.e., OA, palmitoleic) have been related to the prevention of metabolic alterations (lipid metabolism disturbances, inflammation, and IR) or chronic diseases (obesity, T2D, non-alcoholic fatty liver disease, cardiovascular risk and some types of cancer). On the other hand, n-6 PUFA, such as AA, SFA (stearic and palmitic), and TFA (elaidic acid), have been associated with the presence or development of obesity, T2D, inflammatory profile, atherosclerosis, hyperglycemia, IR, lipid alterations, lipotoxicity, dysregulation of lipid metabolism, and abnormal lipid accumulation (Fig. 2).

Concerning the effects of n-3 PUFA on the DNA methylation status, a possible mechanism that has been proposed is that $\mathrm{n}-3$ PUFA can promote the conversion from $\mathrm{C}$ to $5 \mathrm{mC}$ conducted by DNA methyltransferases (DNMTs) by enhancing the expression of DNMTs and consequently influence DNA methylation [20]. Furthermore, a potential interaction between n-3 PUFA and MeCP2 (methyl CpG binding protein 2) has been proposed, mainly in promoter regions, and consequently could be associated with the regulation of gene expression [50]. Another possible mechanism by which n-3 PUFAs can affect methylation is that these FA are natural ligands of some transcriptional factors, such as PPAR $y$ [51]. In this context, it has been reported that interactions between PPAR $\gamma$ and fatty acids result in a decrease in cytokine expression [52], and in murine models, Pparg expression is modulated by DNA methylation in its promoter region [61]. However, more studies are needed to elucidate the role of FA in the regulation of epigenetic mechanisms in the context of metabolic alterations and chronic diseases. Regarding the other types of FA, a specific mechanism in which they could alter epigenetic landmarks, has not been described.

The intake and supplementation of different types of FA has demonstrated to have an effect on transgenerational epigenetic mechanisms (being DNA methylation the most studied). These effects are implicated in the pathogenic or protective role of FA and can be modulated during pregnancy and lactation, suggesting that they could be interesting therapeutic targets.

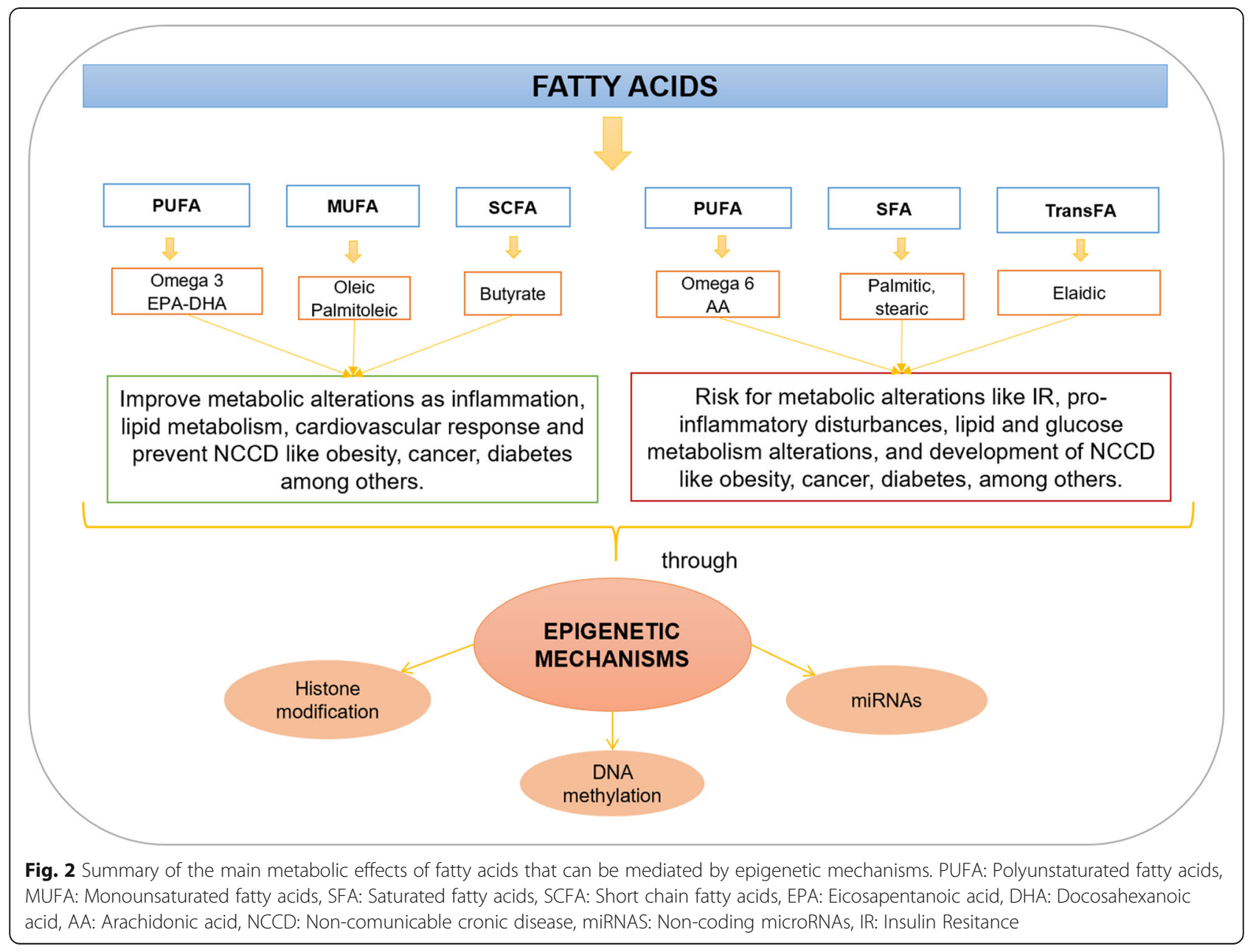


In this term the role of nutraceuticals as a potent effect on lipids regulation should be considered, and more investigations are necessary to elucidate the role of nutraceuticals depending of the individual genetic variability [63], and their possible effect on epigenetic modifications for finally encourage the management of metabolic diseases as an integrative treatment.

SCFA are especially interesting because they take part of a diet-microbiota-epigenetics axis. For example, butyrate is a potent non-competitive HDAC inhibitor that is implicated in the regulation of gene expression. However, more studies are necessary to understand the regulation of specific genes and consequently their metabolic effects, as well as to consider the integrative effect of other components like gut microbiota, because butyrate is mainly produced by gut microbes, so the interaction will be very important to understand the complete outcome [64].

The epigenetic and metabolic effects of the different types of FA depend on the dose and the model, but many examples demonstrate that they can modulate the epigenome. Nevertheless, more studies are necessary to clarify the specific genes and pathways that are affected by FA through epigenetic mechanisms and consider other nutritional components that have an effect on epigenetic landmarks, such as methyl donors (vitamin $\mathrm{B}_{12}$, folate, choline, betaine, methionine, serine, glycine, and histidine), vitamins (retinol, tocopherols, and ascorbate), and polyphenols (epigallocatechin 3-gallate, genistein, curcumin, resveratrol, and sulforaphane, among others).

\section{Supplementary information}

Supplementary information accompanies this paper at https://doi.org/10. 1186/s12944-019-1120-6.

Additional file 1. Search strategy and data extraction.

\section{Abbreviations \\ AA: Arachidonic acid; CVD: Cardiovascular Disease; DHA: Docosahexaenoic acid; DMRs: Differentially methylated regions; DNMTs: DNA \\ methyltransferases; EA: Elaidic acid; EPA: Eicosapentaenoic; FA: Fatty acids; HDAC: Histone deacetylases; IR: Insulin Resistance; MBD2: Methyl-CpG- binding domain protein 2; MUFA: Monosaturated fatty acids; NaB: Sodium butyrate; NCCD: Non-comunicable chronic disease; NEFA: Non-esterified fatty acids; OA: Oleic acid; PUFA: Polyunsaturated fatty acids; SCFA: Short chain fatty acids; SFA: Saturated fatty acids; T2D: Type 2 Diabetes; TFA: Trans fatty acids}

\section{Acknowledgements}

Spanish Biomedical Research Centre in Physiopathology of Obesity and Nutrition (CIBERobn), Institute of Health Carlos III, Madrid, Spain and IdiSNA, University of Navarra, Pamplona, Spain. University of Guadalajara, Jalisco, Mexico and Autonomous University of Baja California, Mexico.

\section{Authors' contributions}

$K G B, E B C$ and ORL were substantially involved in the inclusion of the scientific contents and bibliographical search as well as in the careful reading and discussion of the final version JAM, and EML contributed with funds, initial designed, as well as in the manuscript preparation and discussion FIM and JIRB participated in data analysis and interpretation. All authors read and approved the final manuscript.

Funding

Not applicable.

Availability of data and materials

Not applicable.

Ethics approval and consent to participate

Not applicable.

\section{Consent for publication}

Not applicable.

\section{Competing interests}

The authors declare that they have no competing interests.

\section{Author details}

'Institute of Traslational Nutrigenetics and Nutrigenomics, Health Sciences University Center, University of Guadalajara, Guadalajara, Jalisco, Mexico. ${ }^{2}$ Department of Nutrition, Food Science, Physiology and Toxicology, Centre for Nutrition Research, University of Navarra, Pamplona, Spain. ${ }^{3}$ Faculty of Medicine and Psychology, Autonomous University of Baja California, Tijuana, B.C., Mexico. ${ }^{4}$ Navarra Institute for Health Research (IdiSNA), Pamplona, Spain. ${ }^{5}$ Centro de Investigación Biomédica en Red Fisiopatología de la Obesidad y Nutrición (CIBERobn), Carlos III Health Institute, Madrid, Spain. ${ }^{6}$ Department of Molecular Biology in Medicine, Health Sciences University Center, University of Guadalajara, Sierra Mojada 950, 44340 Guadalajara, Jalisco,

Mexico. ${ }^{7}$ Madrid Institute of Advanced Studies (IMDEA Food), Madrid, Spain.

Received: 1 April 2019 Accepted: 30 September 2019

Published online: 15 October 2019

\section{References}

1. Sharp GC, Relton CL. Epigenetics and noncommunicable diseases. Epigenomics. 2017:19:789-91.

2. García-Robles R, Ayala-Ramirez PA, Perdomo-Velásquez SA. Epigenética: definición, bases moleculares e implicaciones en la salud y en la evolución humana. Rev Ciencias Salud. 2012;10:59-71.

3. Corella D, Ordovas JM. Basic concepts in molecular biology related to genetics and epigenetics. Rev Esp Cardiol (Engl Ed). 2017;70:744-53.

4. Martínez JA, Milagro Fl, Claycombe KJ, Schalinske KL. Epigenetics in adipose tissue, obesity, weight loss, and diabetes. Adv Nutr. 2014:5:71-81.

5. Handy DE, Castro R, Loscalzo J. Epigenetic modifications: basic mechanisms and role in cardiovascular disease. Circulation. 2011;123:2145-56.

6. Bollati V, Baccarelli A. Environmental Epigenetics. Heredity. 2010;105:105-12.

7. Milagro Fl, Mansego ML, De Miguel C, Martínez JA. Dietary factors, epigenetic modifications and obesity outcomes: progresses and perspectives. Mol Asp Med. 2013;34:782-812.

8. Kulkarni A, Dangat K, Kale A, Sable P, Chavan-Gautam P, Joshi S. Effects of altered maternal folic acid, vitamin B12 and docosahexaenoic acid on placental global DNA methylation patterns in Wistar rats. PLoS One. 2011;6: e17706.

9. Kiec-Wilk B, Sliwa A, Mikolajczyk M, Malecki MT, Mathers JC. The CpG island methylation regulated expression of endothelial proangiogenic genes in response to $\beta$-carotene and arachidonic acid. Nutr Cancer. 2011;63:1053-63.

10. Lee C, Kim BG, Kim JH, Chun J, Im JP, Kim JS. Sodium butyrate inhibits the NF-kappa B signaling pathway and histone deacetylation and attenuates experimental colitis in an IL-10 independent manner. Int Immunopharmacol. 2017;51:47-56.

11. Cordain L, Eaton SB, Sebastian A, Mann N, Lindeberg S, Watkins BA. Origins and evolution of the Western diet: health implications for the 21st century. Am J Clin Nutr. 2005;81:341-54

12. Morgen CS, Sørensen TA. Obesity: global trends in the prevalence of overweight and obesity. Nat Rev Endocrinol. 2014;10:513-4.

13. Daar AS, Singer PA, Persad DL, Pramming SK, Matthews DR, Beaglehole R, Bernstein A, Borysiwicz LK. Grand challenges in chronic non-communicable diseases. Nature. 2007:450:494-6.

14. Ramos-Lopez O, Milagro Fl, Allayee H, Chmurzynska A, Choi MS, Curi R, et al. Guide for current Nutrigenetic, Nutrigenomic, and Nutriepigenetic 
approaches for precision nutrition involving the prevention and Management of Chronic Diseases Associated with obesity. J Nutrigenet Nutrigenomics. 2017;10:43-62.

15. Urrútia G, Bonfill X. Declaración PRISMA: una propuesta para mejorar la publicación de revisiones sistemáticas y metaanálisis. Med Clínica. 2010;135:507-11.

16. Tremblay BL, Guénard F, Rudkowska I, Lemieux S, Couture P, Vohl MC. Epigenetic changes in blood leukocytes following an omega-3 fatty acid supplementation. Clin Epigenetics. 2017;9:43.

17. Aslibekyan S, Wiener HW, Havel PJ, Stanhope KL, O'Brien DM, Hopkins SE, et al. DNA methylation patterns are associated with n-3 fatty acid intake in Yup'ik people. J Nutr. 2014;144:425-30.

18. Arpón A, Milagro Fl, Razquin C, Corella D, Estruch R, Fitó M, Marti A, Martínez-González MA, Ros E, Salas-Salvadó J, Riezu-Boj Jl, Martínez JA. Impact of consuming extra-virgin olive oil or nuts within a Mediterranean diet on DNA methylation in peripheral white blood cells within the PREDIMED-Navarra randomized controlled trial: a role for dietary lipids. Nutrients. 2018;10:1-15.

19. do Amaral CL, Milagro Fl, Curi R, Martínez JA. DNA methylation pattern in overweight women under an energy-restricted diet supplemented with fish oil. BioMed Res Int. 2014;2014:1-10.

20. Hermsdorff HH, Mansego ML, Campión J, Milagro Fl, Zulet MA, Martínez JA. TNF-alpha promoter methylation in peripheral white blood cells: relationship with circulating TNFa, truncal fat and n-6 PUFA intake in young women. Cytokine. 2013;64:265-71.

21. Lee H-S, Barraza-Villarreal A, Biessy C, Duarte-Salles T, Sly PD, Ramakrishnan $U$, et al. Dietary supplementation with polyunsaturated fatty acid during pregnancy modulates DNA methylation at IGF2/H19 imprinted genes and growth of infants. Physiol Genomics. 2014;46:851-7.

22. van Dijk SJ, Zhou J, Peters TJ, Buckley M, Sutcliffe B, Oytam Y, et al. Effect of prenatal DHA supplementation on the infant epigenome: results from a randomized controlled trial. Clin Epigenetics. 2016;8:1-14

23. Huang Q, Wen J, Chen G, Ge M, Gao Y, Ye X, et al. Omega-3 polyunsaturated fatty acids inhibited tumor growth via preventing the decrease of genomic DNA methylation in colorectal Cancer rats. Nutr Cancer. 2016;68:113-9.

24. Shen W, Wang C, Xia L, Fan C, Dong H, Deckelbaum RJ, et al. Epigenetic modification of the Leptin promoter in diet-induced obese mice and the effects of N-3 polyunsaturated fatty acids. Sci Rep. 2014:4:1-8.

25. Boddicker RL, Koltes JE, Fritz-Waters ER, Koesterke L, Weeks N, Yin T, et al. Genome-wide methylation profile following prenatal and postnatal dietary omega-3 fatty acid supplementation in pigs. Anim Genet. 2016;47:658-71.

26. Silva-Martínez GA, Rodríguez-Ríos D, Alvarado-Caudillo Y, Vaquero A, Esteller M, Carmona FJ, et al. Arachidonic and oleic acid exert distinct effects on the DNA methylome. Epigenetics. 2016;11:321-34.

27. Flores-Sierra J, Arredondo-Guerrero M, Cervantes-Paz B, Rodríguez-Ríos D, Alvarado-Caudillo Y, Nielsen FC, et al. The trans fatty acid elaidate affects the global DNA methylation profile of cultured cells and in vivo. Lipids Health Dis. 2016;15:1-7.

28. Desgagné $V$, Guérin $R$, Guay SP, Corbin F, Couture $P$, Lamarche $B$, et al. Changes in high-density lipoprotein-carried miRNA contribution to the plasmatic pool after consumption of dietary trans fat in healthy men. Epigenomics. 2017;9:669-88.

29. Kumar S, Pamulapati H, Tikoo K. Fatty acid induced metabolic memory involves alterations in renal histone H3K36me2 and H3K27me3. Mol Cell Endocrinol. 2016:422:233-42.

30. Hall E, Volkov P, Dayeh T, Bacos K, Rönn T, Nitert MD, et al. Effects of palmitate on genome-wide mRNA expression and DNA methylation patterns in human pancreatic islets. BMC Med. 2014;12:1-15.

31. Ishikawa K, Tsunekawa S, Ikeniwa M, Izumoto T, lida A, Ogata H, et al. Longterm pancreatic beta cell exposure to high levels of glucose but not palmitate induces DNA methylation within the insulin gene promoter and represses transcriptional activity. PLoS One. 2015;10:1-19.

32. Maples JM, Brault JJ, Shewchuk BM, Witczak CA, Zou K, Rowland N, et al. Lipid exposure elicits differential responses in gene expression and DNA methylation in primary human skeletal muscle cells from severely obese women. Physiol Genomics. 2015:47:139-46.

33. Wang X, Cao Q, Yu L, Shi H, Xue B, Shi H. Epigenetic regulation of macrophage polarization and inflammation by DNA methylation in obesity. JCl Insight. 2016;1:1-20.

34. Khan S, Jena GB. Protective role of sodium butyrate, a HDAC inhibitor on beta-cell proliferation, function and glucose homeostasis through modulation of p38/ERK MAPK and apoptotic pathways: study in juvenile diabetic rat. Chem Biol Interact. 2014:213:1-12

35. Henagan TM, Stefanska B, Fang Z, Navard AM, Ye J, Lenard NR, et al. Sodium butyrate epigenetically modulates high-fat diet-induced skeletal muscle mitochondrial adaptation, obesity and insulin resistance through nucleosome positioning. Br J Pharmacol. 2015;172:2782-98.

36. Mátis G, Neogrády Z, Csikó G, Gálfi P, Fébel H, Jemnitz K, et al. Epigenetic effects of dietary butyrate on hepatic histone acetylation and enzymes of biotransformation in chicken. Acta Vet Hung. 2013;61:477-90.

37. Huang Y, Gao S, Chen J, Albrecht E, Zhao R, Yang X. Maternal butyrate supplementation induces insulin resistance associated with enhanced intramuscular fat deposition in the offspring. Oncotarget. 2017;8:13073-84

38. Wippermann A, Rupp O, Brinkrolf $K$, Hoffrogge R, Noll T. Integrative analysis of DNA methylation and gene expression in butyrate-treated $\mathrm{CHO}$ cells. J Biotechnol. 2017:257:150-61.

39. Shin JH, Xu L, Li RW, Gao Y, Bickhart D, Liu GE, et al. A high-resolution whole-genome map of the distinctive epigenomic landscape induced by butyrate in bovine cells. Anim Genet. 2014;1:40-50.

40. Lin MY, de Zoete MR, van Putten JP, Strijbis K. Redirection of epithelial immune responses by short-chain fatty acids through inhibition of histone Deacetylases. Front Immunol. 2015;6:1-11.

41. Paskova L, Smesny-Trtkova K, Fialova B, Benedikova A, Langova K, Kolar Z. Different effect of sodium butyrate on cancer and normal prostate cells. Toxicol in Vitro. 2013;27:1489-95.

42. Shin H, Kim JH, Lee YS, Lee YC. Change in gene expression profiles of secreted frizzled-related proteins (SFRPs) by sodium butyrate in gastric cancers: induction of promoter demethylation and histone modification causing inhibition of Wnt signaling. Int J Oncol. 2012;40:1533-42.

43. Mathew OP, Ranganna K, Yatsu FM. Butyrate, an HDAC inhibitor, stimulates interplay between different posttranslational modifications of histone $\mathrm{H} 3$ and differently alters G1-specific cell cycle proteins in vascular smooth muscle cells. Biomed Pharmacother. 2010;64:733-40.

44. Cho Y, Turner ND, Davidson LA, Chapkin RS, Carroll RJ, Lupton JR. Colon cancer cell apoptosis is induced by combined exposure to the n-3 fatty acid docosahexaenoic acid and butyrate through promoter methylation. Exp Biol Med. 2014:239:302-10.

45. Perfilyev A, Dahlman I, Gillberg L, Rosqvist F, Iggman D, Volkov P, et al. Impact of polyunsaturated and saturated fat overfeeding on the DNAmethylation pattern in human adipose tissue: a randomized controlled trial. Am J Clin Nutr. 2017;105:991-1000.

46. Voisin S, Almén MS, Moschonis G, Chrousos GP, Manios Y, Schiöth HB. Dietary fat quality impacts genome-wide DNA methylation patterns in a cross-sectional study of Greek preadolescents. Eur J Hum Genet. 2015;23: 654-62.

47. Lind MV, Martino D, Harsløf LB, Kyjovska ZO, Kristensen M, Lauritzen L. Genome-wide identification of mononuclear cell DNA methylation sites potentially affected by fish oil supplementation in young infants: a pilot study. Prostaglandins Leukot Essent Fatty Acids. 2015;101:1-7.

48. de la Rocha C, Pérez-Mojica JE, Zenteno-De León S, Cervantes-Paz B, TristánFlores FE, Rodríguez-Ríos D, et al. Associations between whole peripheral blood fatty acids and DNA methylation in humans. Sci Rep. 2016;6:1-11.

49. García-Escobar E, Monastero R, García-Serrano S, Gómez-Zumaquero JM, Lago-Sampedro A, Rubio-Martín E, et al. Dietary fatty acids modulate adipocyte TNFa production via regulation of its DNA promoter methylation levels. J Nutr Biochem. 2017:47:106-12.

50. Monastero R, García-Serrano S, Lago-Sampedro A, Rodríguez-Pacheco F, Colomo N, Morcillo S, et al. Methylation patterns of Vegfb promoter are associated with gene and protein expression levels: the effects of dietary fatty acids. Eur J Nutr. 2017;56:715-26.

51. Hoile SP, Irvine NA, Kelsall CJ, Sibbons C, Feunteun A, Collister A, et al. Maternal fat intake in rats alters 20:4n-6 and 22:6n-3 status and the epigenetic regulation of Fads2 in offspring liver. J Nutr Biochem. 2013;24: 1213-20.

52. Casas-Agustench P, Fernandes FS, Tavares do Carmo MG, Visioli F, Herrera E, Dávalos A. Consumption of distinct dietary lipids during early pregnancy differentially modulates the expression of microRNAs in mothers and offspring. PLoS One. 2015;10:1-17.

53. Huerta AE, Prieto-Hontoria PL, Fernández-Galilea M, Escoté X, Martínez JA, Moreno-Aliaga MJ. Effects of dietary supplementation with EPA and/or alipoic acid on adipose tissue transcriptomic profile of healthy overweight/ obese women following a hypocaloric diet. Biofactors. 2017;43:117-31. 
54. Orsavova J, Misurcova L, Ambrozova JV, Vicha R, Mlcek J. Fatty acids composition of vegetable oils and its contribution to dietary energy intake and dependence of cardiovascular mortality on dietary intake of fatty acids. Int J Mol Sci. 2015;16:12871-90.

55. Frigolet ME, Gutierrez-Aguilar R. The role of the novel Lipokine palmitoleic acid in health and disease. Adv Nutr. 2017:8:173-81.

56. Bergman EN. Energy contributions of volatile fatty acids from the gastrointestinal tract in various species. Physiol Rev. 1990;70:567-90.

57. Arents G, Burlingame RW, Wang BC, Love WE, Moudrianakis EN. The nucleosomal core histone octamer at 3.1 a resolution: a tripartite protein assembly and a left-handed superhelix. Proc Natl Acad Sci. 1991;88:10148-52.

58. Goldberg AD, Allis CD, Bernstein E. Epigenetics: a landscape takes shape. Cell. 2007;128:635-8.

59. Li RW, Li C. Butyrate induces profound changes in gene expression related to multiple signal pathways in bovine kidney epithelial cells. BMC Genomics. 2006;7:1-14.

60. Lovis P, Roggli E, Laybutt DR, Gattesco S, Yang JY, Widman C, Abderrahmani $A$, Regazzi R. Alterations in MicroRNA expression contribute to fatty acidinduced pancreatic $\beta$-cell dysfunction. Diabetes. 2008;57:2728-36.

61. Benatti RO, Melo AM, Borges FO, Ignacio-Souza LM, Simino LA, Milanski M, et al. Maternal high-fat diet consumption modulates hepatic lipid metabolism and microRNA-122 (miR-122) and microRNA-370 (miR-370) expression in offspring. Br J Nutr. 2014;111:2112-22.

62. Zhang J, Zhang F, Didelot X, Bruce KD, Cagampang FR, Vatish $M$, et al. Maternal high fat diet during pregnancy and lactation alters hepatic expression of insulin like growth factor-2 and key microRNAs in the adult offspring. BMC Genomics. 2009;10:1-12.

63. Scicchitano P, Cameli M, Maiello M, et al. Nutraceuticals and dyslipidaemia: beyond the common therapeutics. J Functional Foods. 2014;6:11-32.

64. Kasubuchi M, Hasegawa S, Hiramatsu T, Ichimura A, Kimura I. Dietary gut microbial metabolites, short-chain fatty acids, and host metabolic regulation. Nutrients. 2015;7:2839-49.

\section{Publisher's Note}

Springer Nature remains neutral with regard to jurisdictional claims in published maps and institutional affiliations.

Ready to submit your research? Choose BMC and benefit from:

- fast, convenient online submission

- thorough peer review by experienced researchers in your field

- rapid publication on acceptance

- support for research data, including large and complex data types

- gold Open Access which fosters wider collaboration and increased citations

- maximum visibility for your research: over $100 \mathrm{M}$ website views per year

At $\mathrm{BMC}$, research is always in progress.

Learn more biomedcentral.com/submissions 